\title{
INDUÇÃO DE ALTERAÇÕES MORFOLÓGICAS E ANATÔMICAS EM FOLHAS DE ABACAXIZEIRO 'PÉROLA' PELO ÁCIDO 2-(3-CLOROFENOXI) PROPIÔNICO'
}

\author{
NATHÁLIA MARIA LARANJEIRA BARBOSA², GETÚLIO AUGUSTO PINTO DA CUNHA ${ }^{3}$, DOMINGO HAROLDO \\ REINHARDT ${ }^{3}$, PÉRICLES GABRIEL BARROS ${ }^{4}$, ANA RITA LEANDRO DOS SANTOS ${ }^{5}$
}

\begin{abstract}
RESUMO - Em estudo que visou controlar a floração natural do abacaxizeiro 'Pérola' com fitorreguladores, nas plantas pulverizadas com 50 e 100 mg $\mathrm{L}^{-1}$ (3 aplicações) do ácido 2-(3-clorofenoxi) propiônico (ACP), foram observadas alterações internas e externas nas folhas. O limbo foliar apresentou ligeiro estrangulamento na porção mediana das folhas ' $E$ ' e ' $F$ ' e próximo ao ponto de inserção no caule nas C'e ' $D$ '. A cerca de 5-10 cm desse ponto surgiram estruturas similares a calos, que originaram raízes adventícias. A roseta central das plantas apresentou-se torcida, com as folhas mais curtas e largas. Cortes anatômicos permitiram observar, sob microscópio óptico (40X), que as raízes adventícias foram formadas a partir de meristemas nos feixes vasculares (xilema e floema), e que a estrutura anatômica foliar nos pontos de estrangulamento do limbo não foi alterada. Parênquima assimilador formou-se no córtex dessas raízes adventícias, indicando a realização de fotossíntese nesse tecido. A localização das raízes adventícias nas folhas correspondeu às áreas de provável acúmulo do produto pulverizado sobre as plantas. Os efeitos causados pelo ACP neste trabalho sugerem o seu uso em estudos relacionados à indução de enraizamento na propagação vegetativa (convencional e micropropagação) e na formação de calos "in vitro". E servem, também, para orientar novos estudos sobre a inibição da floração natural e seu uso prático, a fim de se evitar danos às plantas.
\end{abstract}

Termos para indexação: Ananas comosus, abacaxi, regulador de crescimento vegetal, raízes adventícias.

\section{INDUCTION OF LEAF MORPHOLOGICAL AND ANATOMICAL ALTERATIONS ON 'PÉROLA' PINEAPPLE LEAVES BY THE 2-(3-CHLOROPHENOXY) PROPIONIC ACID}

ABSTRACT - In a study $w$ ith the objective of controlling the natural precocious flowering in pineapple 'Perola', the plants treated with the 2-(3chlorophenoxy) propionic acid-CPA(50 and $100 \mathrm{mg} \mathrm{L}^{-1}, 3$ applications) showed some internal and external modifications in the leaves. The young ' $\mathrm{E}$ ' and ' $\mathrm{F}$ ' leaves presented small constrictions on the central portion of their limbs, while on the ' $\mathrm{C}$ ' and ' $\mathrm{D}$ ' ones, those constrictions were observed near to their bases. At about $5-10 \mathrm{~cm}$ from that point emerged some structures similar to a callus, on which originated adventitious roots. The central rosette showed shorter and wider leaves. Anatomical cuttings of the leaves, observed under optical microscope (40X), showed that the adventitious roots were originated from meristems found in the vascular bundles (xylem and phloem), and that the anatomical structure of the leaves, on the constriction points, was not modified. Assimilative parenchyma was observed on the cortex of those adventitious roots, suggesting that this tissue carried on photosynthesis. The localization of the adventitious roots corresponded probably to the point of accumulation of the applied product on the leaves. Those effects suggest the possibility of CPA use in studies of rooting induction in conventional vegetative propagation and micropropagation, and in callus formation "in vitro". And also, to guide new studies on natural flowering inhibition and its practical use, in order to avoid damage to the plants.

Index terms: Ananas comosus, growth regulator, adventitious roots

\section{INTRODUÇÃO}

A indução artificial da floração na cultura do abacaxi por meio de reguladores de crescimento vegetal tem sido amplamente empregada há bastante tempo, com a finalidade de antecipar a colheita. O uso de fitohormônios para induzir a floração, em combinação com a época de plantio e tamanho de muda, ajuda o produtor a programar a colheita, evitando a superprodução no período de safra normal ou ampliar o período de colheita, de acordo com a conveniência do mercado.

A indução da floração é apenas um dos possíveis usos de fitorreguladores na cultura do abacaxizeiro. Os vários tipos de substâncias, seus diferentes efeitos sobre a planta e as distintas respostas desta, a depender do tempo de aplicação e concentração, são empregados na expectativa de obter-se um maior controle do desenvolvimento da planta e do fruto (Cunha et al., 1994). Entretanto, a inibição da floração é, também, uma técnica praticada em outras culturas, a exemplo de algumas plantas floríferas, a fim de fazer coincidir a colheita com datas festivas, quando os preços de venda são mais compensadores (Nickell, 1982). Atualmente, tal tecnologia tem sido cogitada para uso na cultura do abacaxi.

Sabe-se que o florescimento natural do abacaxizeiro é desuniforme, dificultando o manejo da cultura, principalmente quando ocorre precocemente, refletindo negativamente na comercialização dos frutos, que geralmente tornam-se menores e menos pesados. Esse florescimento está se tornando cada vez mais freqüente nas várias regiões produtoras de abacaxi do mundo, motivando a realização de pesquisas, com vistas a reduzir sua ocorrência. Diversos estudos envolvendo a avaliação de efeitos de diferentes fitorreguladores sobre a diferenciação floral, mostraram que alguns deles, quando usados em concentrações elevadas, retardaram a diferenciação floral. Scott (1993), na Austrália, e Rebolledo-Martínez et al. (1997), no México, usando o ácido 2-(3clorofenoxi) propiônico (ACP) para inibir a floração natural do abacaxizeiro, obtiveram resultados satisfatórios, que demonstraram a eficiência desse produto com a referida finalidade. O ACPé um regulador de crescimento usado para promover o aumento do tamanho e massa do fruto, atraso na maturação e redução do crescimento da coroa do abacaxizeiro.

No entanto, em algumas pesquisas efetuadas com o objetivo de inibir a floração natural do abacaxizeiro, têm sido observados alguns efeitos colaterais, a exemplo de anomalias e até mesmo morte de plantas, causadas pelos reguladores de crescimento usados, principalmente, pelo ACP, conforme relatado por Min \& Bartholomew (1993), RebolledoMartínez et al. (1997) e Barbosa (1997).

Neste trabalho são apresentadas e discutidas, portanto, as alterações morfológicas e anatômicas causadas pelo ácido 2-(3-clorofenoxi) propiônico em plantas de abacaxizeiro 'Pérola', observadas em um experimento cujo objetivo era controlar a floração natural da referida planta.

\footnotetext{
${ }^{1}$ (Trabalho 133/2002). Recebido: 21/10/2003. Aceito para publicação: 28/08/2003. Parte da dissertação do primeiro autor, apresentada à AGRUFBA, para obtenção do título de Mestre.

${ }^{2}$ Eng $^{\circ}$. Agr ${ }^{\circ}$., M. Sc., HIDROS- Formoso A, Rod. BR 349, 47.600-000, Bom Jesus da Lapa/BA, nathalia@pollynet.com.br .

${ }^{3}$ Eng $^{\circ}$. Agro ${ }^{\circ}$., D. Sc., Pesquisadores da Embrapa Mandioca e Fruticultura, C. P. 007, 44.380-000, Cruz das Almas/BA, tels. (75) 621-8142 e -8061, getulio@cnpmf.embrapa.br/dharoldo@cnpmf.embrapa.br

${ }^{4}$ Eng $^{\circ}$. Agr. ., M. Sc., EPEAL, Rua 17 de Agosto, 125, 57.120-000, Satuba/AL, pgb@epeal.al.gov.br.

${ }^{5}$ Eng $^{\circ}$. Agr ${ }^{\circ}$., M. Sc., CEFET, Rod. BR 235, Km 22, N4, Projeto Nilo Coelho, 56.300-000 Petrolina/PE, anaritaleandro@ig.com.br
} 


\section{MATERIALEMÉTODOS}

O experimento, plantado em novembro de 1995, foi realizado na Embrapa Mandioca e Fruticultura, em Cruz das Almas/BA, cujas localização geográfica e médias climáticas anuais são as seguintes: 1240'39" $\mathrm{S}$; 39॰06' 23" W; altitude $225 \mathrm{~m}$; pluviosidade $1.224 \mathrm{~mm}$; temperatura $24^{\circ} \mathrm{C}$; umidade relativa do ar $80 \%$.

O delineamento experimental foi de blocos ao acaso, esquema fatorial de $4 \times 2+1$ (produtos $x$ concentrações + testemunha), com cinco repetições. As parcelas foram constituídas de 36 plantas úteis, da cultivar Pérola, usando-se mudas do tipo filhote, com $25-35 \mathrm{~cm}$ de comprimento e peso de 250-300 g. As soluções com os produtos foram aplicadas três vezes ( $\left.50 \mathrm{~mL}_{\text {planta }}{ }^{-1}\right)$, com intervalos de 15 dias, nos meses de junho e julho de 1996, período crítico para a floração natural na região. As concentrações (i. a.) dos tratamentos foram as seguintes: ácido 2-(3clorofenoxi) propiônico - $\mathrm{ACP}\left(50\right.$ e $\left.100 \mathrm{mg} \mathrm{L}^{-1}\right)$; paclobutrazol - PCB (50 e $\left.100 \mathrm{mg} \mathrm{L}^{-1}\right)$; cloreto de mepiquat - CM (80 e $\left.160 \mathrm{mg} \mathrm{L}^{-1}\right)$; uréia - U (líquida, $5 \%$ e sólida, $1,5 \mathrm{~g}_{\text {planta }}{ }^{-1}$ ); testemunha (água fria).

As avaliações, referentes à inibição da floração, foram realizadas semanalmente, a partir de 12 de julho, para a primeira época, e de 12 de agosto, para a segunda época, ou seja, 42 dias após a primeira aplicação dos produtos nos referidos períodos. Além disso, foram efetuadas observações visuais sobre a ocorrência de anomalias induzidas nas plantas pelos fitorreguladores, em ambas as épocas, e coletadas folhas que apresentaram modificações em sua morfologia e anatomia, para avaliação em microscópio óptico de 40X, no Laboratório de Fitopatologia, da Embrapa Mandioca e Fruticultura Tropical.

\section{RESULTADOS E DISCUSSÃO}

Neste trabalho são discutidos somente os resultados relacionados às modificações morfológicas e anatômicas causadas pelo ácido 2-(3-clorofenoxi) propiônico-ACP (50 e $100 \mathrm{mg} \mathrm{L}^{-1}$ x 3 aplicações), em folhas e plantas de abacaxi 'Pérola'. Com relação à floração natural, houve apenas uma pequena tendência de inibição/retardamento, mas não foram observadas diferenças entre as concentrações do produto nem em comparação com a testemunha.

Em geral, nos diferentes tratamentos usados, os abacaxizeiros apresentaram características morfológicas normais para a espécie, com exceção das plantas tratadas com o ACP. A partir de 15 dias após a primeira pulverização dos tratamentos, foram verificadas alterações morfológicas externas e internas nas folhas, igualmente nas duas concentrações e épocas estudadas, as quais mantiveram-se no decorrer do trabalho, e cujos aspectos são descritos a seguir:

1- Morfologia das folhas: o limbo foliar apresentou ligeiro estrangulamento na porção mediana das folhas ' $E$ ' e ' $F$ ' (as mais jovens e centrais da roseta foliar) e na região mais próxima ao ponto de inserção no caule das folhas ' $\mathrm{C}$ ' e ' $\mathrm{D}$ ' (as mais velhas e longas produzidas após o plantio); as plantas apresentaram torção da roseta foliar (Figura 1), semelhante ao sintoma de "crook neck" (pescoço torto), causado pela deficiência de $\mathrm{Zn}$, ocorrendo, ainda, em certos pontos, a formação de estruturas parecidas com calos, de onde originaram-se raízes adventícias nas folhas ' $C$ ' e ' $D$ ' (Figura 2); esse aspecto foi observado entre 5-10 $\mathrm{cm}$ da inserção da folha no caule; além disso, as folhas centrais da roseta tornaram-se mais curtas, largas e espessas (Figura 3). Notou-se, ainda, a formação de raízes adventícias que não se originaram de calos aparentes, como descrito anteriormente. Nos demais aspectos morfológicos, as folhas mostraram-se semelhantes às da testemunha e não ocorreu morte de plantas, ao contrário do que foi observado por RebolledoMartínez et al. (1997), certamente devido às concentrações mais altas usadas pelos citados autores (até $200 \mathrm{mg} \mathrm{L}^{-1}$ ).

2-Anatomia das folhas: tendo-se verificado a formação de raízes adventícias a partir do limbo foliar, realizou-se um estudo da organização dos tecidos que constituíam essa estrutura e, em corte transversal, a raiz revelou anatomia típica, apresentando corpo primário. Nesse caso, observou-se que os meristemas formadores do xilema e do floema atuaram na formação dessas raízes, de acordo com a seqüência a seguir:

$\mathbf{a}$ - cortes transversais das folhas mostraram que as células do meristema secundário, que deveriam formar apenas vasos condutores, deram origem ao xilema, no centro, e ao floema, na parte superior do feixe (Figura 4);

b - ainda na parte superior do feixe vascular, na sua porção inferior, as células readquiriram atividade meristemática, dando origem às raízes adventícias (Figura 5).

Nos pontos de estrangulamento do limbo foliar, não foi observada alteração das estruturas que compõem a anatomia da planta. De acordo com observações realizadas em microscópio óptico, com aumento de 400X, pode-se afirmar que as transformações verificadas no limbo foliar tiveram origem nos feixes vasculares. A característica que se destacou no órgão observado foi a presença de parênquima assimilador no córtex da raiz (Figura 6), o que indica a realização de fotossíntese por essa estrutura.

Segundo Damião Filho (1993), quando se utilizam técnicas de cultura de tecidos, as raízes adventícias podem surgir de células indiferenciadas de parênquima (calo), por ação de alguns reguladores de crescimento de efeitos enraizadores, como os ácidos naftalenoacético, indolacético ou indolbutírico. Ainda de acordo com esse mesmo autor, a propagação vegetativa de plantas por meio de estacas é uma das aplicações práticas da formação de raízes adventícias que, nesse caso, podem ter origem no calo que se forma na base do córtex.

Provavelmente, devido ao acúmulo do ACP no ‘olho' da plan-

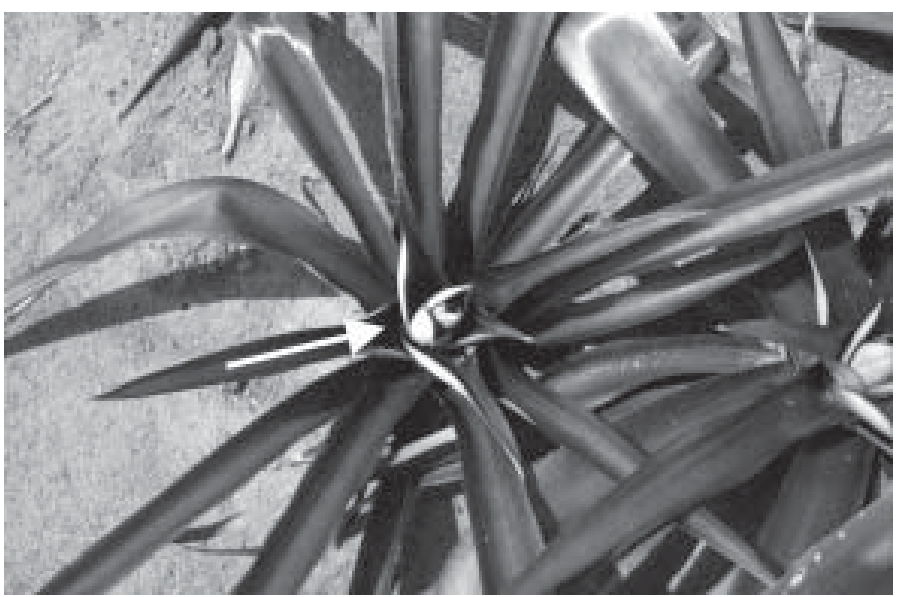

FIGURA 1 - Torção na roseta foliar do abacaxizeiro 'Pérola', causada pelo ácido 2-(3-clorofenoxi) propiônico. Cruz das Almas, BA, 1996. (Autor: Getúlio A. Pinto da Cunha)

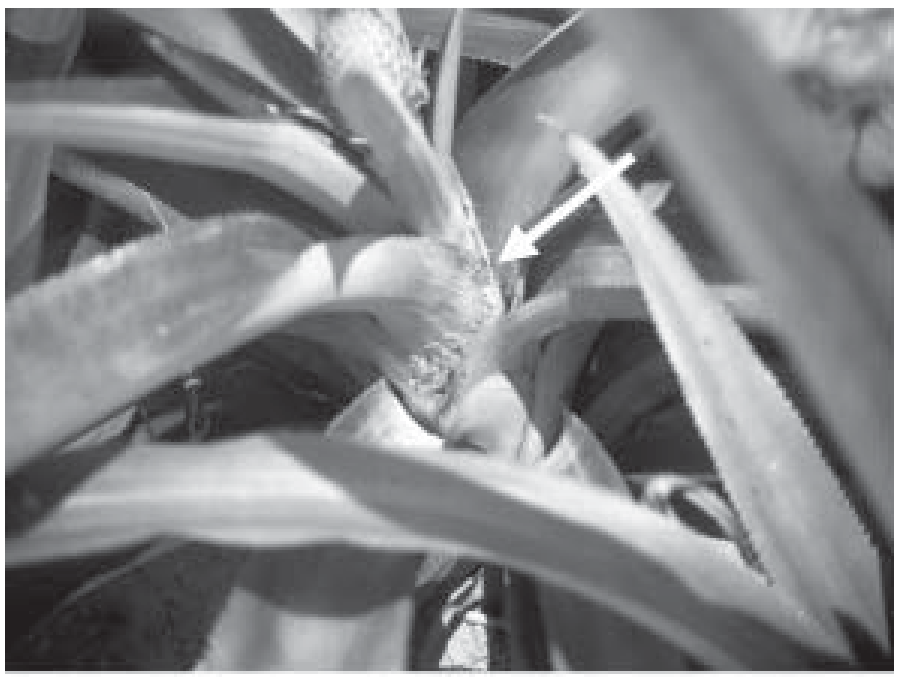

FIGURA 2 - Raízes adventícias originadas em folha de abacaxizeiro 'Pérola', em decorrência da aplicação do ácido 2-(3clorofenoxi) propiônico. Cruz das Almas, BA, 1996. (Autor: GetúlioA. Pinto da Cunha) 


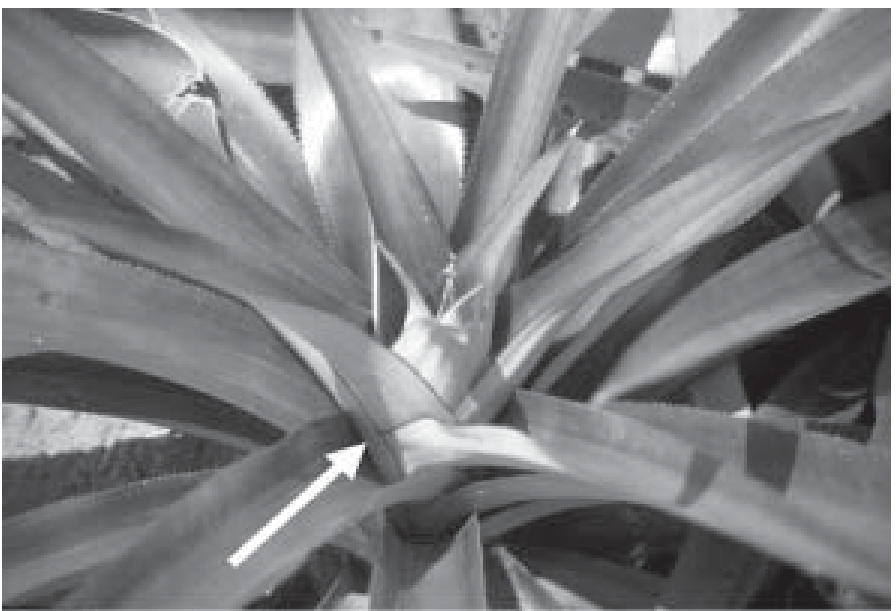

FIGURA 3 - Folhas modificadas (curtas e largas) da roseta central do abacaxizeiro 'Pérola', em função da aplicação do ácido 2(3-clorofenoxi) propiônico. Planta com aspecto de "olho enterrado". Cruz das Almas, BA, 1996. (Autor: Getúlio A. Pinto da Cunha)

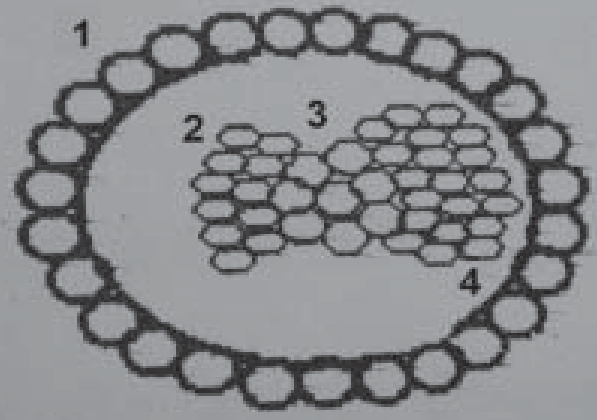

FIGURA 4 - Feixe vascular com massa de células adquirindo atividade meristemática, em folha de abacaxizeiro 'Pérola', em função da aplicação do ácido 2-(3-clorofenoxi) propiônico (corte transversal): 1 . feixe vascular; 2 . floema; 3 . xilema; 4. células diferenciadas para formação de raízes. Cruz das Almas, BA, 1996. (Autora: Ana Rita Leandro dos Santos)

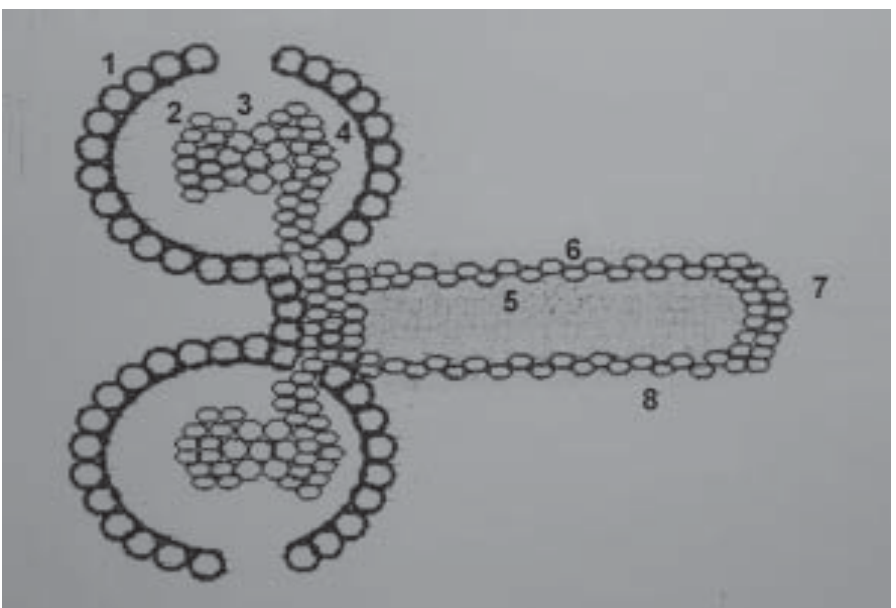

FIGURA 5- Emergência de raiz adventícia a partir de folha de abacaxizeiro 'Pérola', em função da aplicação do ácido 2-(3-clorofenoxi) propiônico (corte transversal): 1. feixe vascular; 2 . floema; 3. xilema; 4. células diferenciadas para formação de raízes; 5. cilindro central; 6 . células corticais; 7. meristema apical; 8. epiderme. Cruz das Almas, BA, 1996. (Autora:Ana Rita Leandro dos Santos) ta, atingindo folhas de diferentes tamanhos, e agindo sobre elas de acordo com a região na qual o produto entrou em contato com sua superfície, parece ter havido uma ação local, promovendo o estrangulamento e torção da roseta foliar e o enraizamento no limbo, independente da época de aplicação. Rebolledo-Martínez et al. (1997) relataram a ocorrência de uma torção na roseta foliar e uma deformação nas folhas de abacaxizeiros tratados com o ACP, as quais foram mais severas com concentrações mais altas ou quando não foram fracionadas. Os referidos autores observaram, em alguns casos, elevada mortalidade de plantas (46\%), com $200 \mathrm{mg} \mathrm{L}^{-1}$, a qual inibiu apenas 39\% da floração. Min \& Bartholomew (1993) informaram que oACP, na concentração de 2,5 mg planta $^{-1}$, danificou o abacaxizeiro, inibindo o alongamento das folhas, inclusive causando a morte de algumas plantas mais jovens, mas que a concentração de $0,5 \mathrm{mg}$ planta $^{-1}$ provocou apenas uma leve torção das folhas.

Apesar das anomalias descritas neste trabalho, não houve mortalidade de plantas, todas recuperaram-se e, ao final do experimento, produziram frutos normais, característicos da cultivar Pérola (Figura 7).

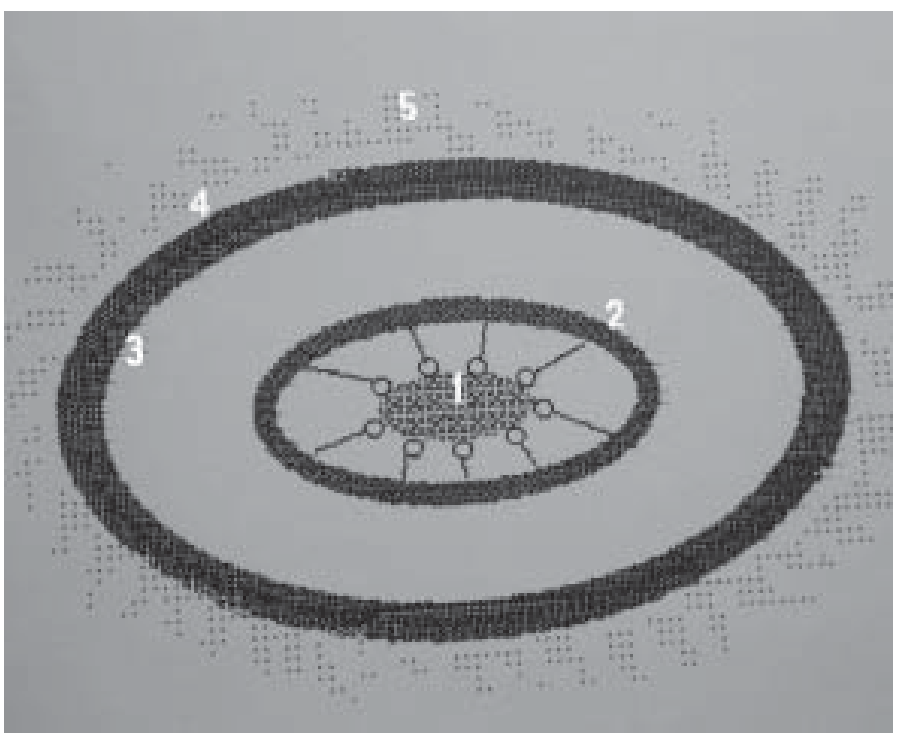

FIGURA 6 -Corte transversal de raízes adventícias, produzidas em folhas de abacaxizeiro 'Pérola', em função da aplicação do ácido 2(3-clorofenoxi) propiônico: 1. cilindro central; 2. córtex; 3 . exoderme; 4. epiderme; 5 . pelos absorventes. Cruz das Almas, BA, 1996. (Autora: Ana Rita Leandro dos Santos)

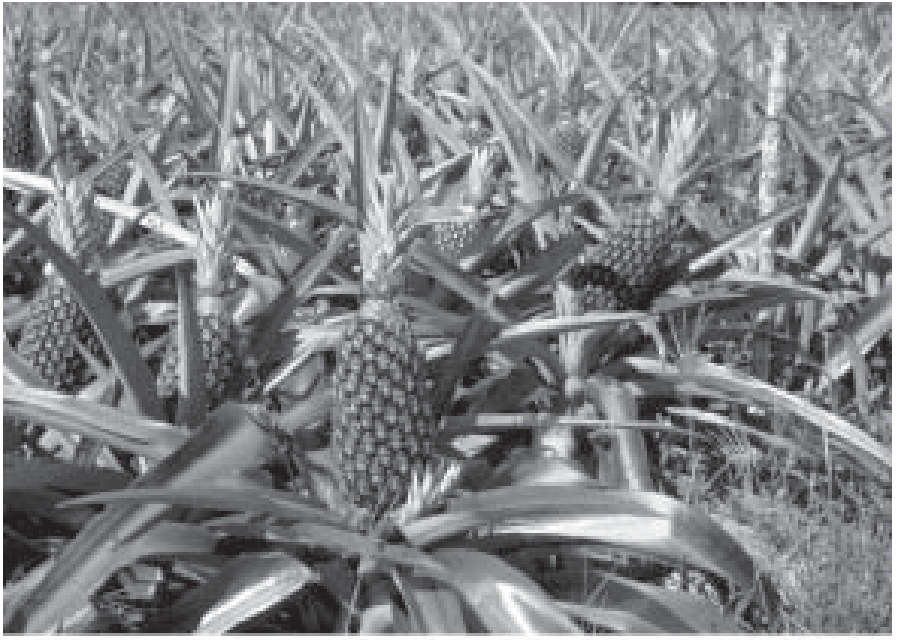

FIGURA 7 - Frutos normais, produzidos por abacaxizeiros da cv. Pérola, que tinham apresentado anomalias anteriormente, em função da aplicação do ácido 2-(3-clorofenoxi) propiônico. Cruz das Almas, BA, 1996. (Autor: Getúlio A. Pinto da Cunha) 


\section{CONCLUSÕES}

Esses fatos sugerem a possibilidade de uso do ácido 2-(3clorofenoxi) propiônico (ACP) em futuras pesquisas, especialmente aquelas relacionadas com a indução de enraizamento na propagação vegetativa convencional e micropropagação e na formação de calos in vitro. E servem, também, para orientar novos estudos sobre a inibição da floração natural e seu uso prático, a fim de se evitar danos às plantas.

\section{REFERÊNCIAS BIBLIOGRÁFICAS}

BARBOSA, N.M.L. Efeito de fitorreguladores e da adubação nitrogenada no controle do florescimento natural precoce do abacaxizeiro. 1997. 59 f. Dissertação (Mestrado em Agronomia/Fitotecnia). AGRUFBA, Cruz das Almas/BA, 1997.

CUNHA, G.A.P. da; MATOS, A.P. de; CABRAL, J.R.S.; SOUZA, L.F. da S.; SANCHES, N.F.; REINHARDT, D.H.R.C.Abacaxi para exporta- ção: aspectos técnicos da produção. Brasília/DF: Embrapa/SPI, 1994. 41 p. (Publicações Técnicas FRUPEX, 11).

DAMIÃO FILHO, C.F. Morfologia vegetal. Jaboticabal,SP: FUNEP/ UNESP, $1993.234 \mathrm{p}$.

MIN, X.J.; BARTHOLOMEW, D.P. Effects of growth regulators on ethylene production and floral initiation of pineapple. Acta Horticulturae, Wageningen, n. 334, p. 101-112, 1993.

NICKELL, L. G Plant growth substances. 3.ed. Kirk-Othmer: Encyclopedia of Chemical Technology, 1982. v. 18, p.1-23.

REBOLLEDO-MARTÍNEZ, A.; URIZA-ÁVILA, D.E.; AGUIRREGUTIÉRREZ, L.A.; PAPALOAN, C.E. Inhibición de la floración de la piña con diferentes dosis de Fruitone CPA en dos densidades de siembra. Acta Horticulturae, Wageningen, n. 425, p. 347-354, 1997.

SCOTT, S.C. The effect of two plant growth regulators on the inhibition of precocious fruiting in pineapple. Acta Horticulturae, Wageningen, n. 334, p. 77-82, 1993. 